\title{
The Relationship between Tropical Forest Stand Variables after a Fire and SPOT XS Satellite Data
}

\author{
Muhamad Buce Saleh Wirakartakusumah and Nobuyuki Abe
}

\begin{abstract}
Forest stand variables provide important information for sound forest management. We developed estimation models for forest stand variables such as number of trees per ha $(N)$, stand basal area $(B A)$ and stand volume $(V)$ of undamaged trees in a tropical forest after a fire. We used the spectral bands of SPOT XS and the transformation bands including the normalized difference vegetation index (NDVI) and inverse vegetation index (IVI) as independent variables. The regression technique was used for the model selection. Stand volume and basal area of undamaged trees were found to be significantly correlated with NDVI and IVI. For stand basal area, the best model was $B A=22.838-28.982$ IVI with $\mathrm{R}^{2}=0.729$; and for stand volume $V=316.707-405.661$ IVI with $\mathrm{R}^{2}=0.791$. Such quantitative forest information may be useful for monitoring the forest.
\end{abstract}

Keyword: forest stand variables, vegetation indices, regression models, tropical forest after fire.

\section{INTRODUCTION}

Deforestation in tropical forests is progressing rapidly due to conversion of land, logging activity, illegal cutting, shifting cultivation, mining, and fire disasters. Recently a ground-cover fire occurred in Indonesia, causing serious damage. In the February-April 1998 period, the concession area of ITCI Ltd. located in East Kalimantan, was burnt by this fire over almost 117,000 ha of the total area of concession. The forest condition has been analyzed by using SPOT Multispectral (XS) satellite data with visual and supervised maximum likelihood classification (JAYA and HusAENI, 1999).

A wide range of stand factors in the burnt forest must be analyzed. This information is needed for determining the best procedures to rehabilitate the forest. Although data on the forest stand variables is important for sound forest management, it is hard to collect the data efficiently by using ground measurement only. The use of satellite or airborne data can be helpful for collection of forest data. However, usually the satellite data is used only for stratification or classification for forest inventories or to serve as a base map.

${ }^{* 1}$ Faculty of Forestry, Bogor Agriculture University, Kampus IPB Darmaga, Po Box 168 Bogor, Indonesia.

${ }^{* 2}$ Faculty of Agriculture, Niigata University, 8050 Ikarashi Ninocho, Niigata, 950-2181, Japan.
Meanwhile, by using satellite data we can estimate the forest characteristics quantitatively. This kind of study is still limited in Forestry Science and need to be developed further.

The satellite data for vegetation cover was obtained with blue, green, red, near infra-red, and middle infra-red spectral bands. In the application of satellite data, the reflectance value obtained with each band and the transformation bands are used, including the indices for vegetation. Several indices for vegetation that were derived from the spectral value of the bands are as follows: Simple Ratio Vegetation Index (SRVI), Normalized Difference Vegetation Index (NDVI), and Transform Vegetation Index (TVI).

In this study, we analyzed and estimated the forest stand variables after a fire, e.g., number of trees per ha, basal area per ha, and volume per ha of undamaged trees by using SPOT XS satellite data. Instead of using the spectral values of each band, we used transformation bands such as NDVI and ratio of XS2 to XS3 (IVI).

\section{METHODS}

Location

This study was conducted in a tropical lowland forest belonging to a forest concession holder, ITCI Ltd. The forest was located in East Kalimantan, near Balikpapan city, at about latitude $0^{\circ} 15^{\prime}-1^{\circ} 0^{\prime}$ South and longitude $116^{\circ} 15^{\prime}-117^{\circ} 0^{\prime}$ East. The logging activity in this forest area started in 1972 . 
According to the vegetation map of the area, which is based on an aerial photo taken in 1990 with a scale of $1: 20000$ and Landsat TM 1994, the forest cover before the fire consisted of: primary lowland forest (36,394ha); swamp forest (17,645ha); logged over lowland forest $(165,920 \mathrm{ha})$; shrubs/secondary forest $(42,613 \mathrm{ha})$; swampy area $(35,263 \mathrm{ha})$, and other uses (7, 350ha). The total area of concession was $283,000 \mathrm{ha}$.

The terrain in this area varied, with an elevation ranging from $10 \mathrm{~m}$ to $600 \mathrm{~m}$ above sea level. Soils in the forest area were predominantly yellow-red podsolic, and only a small part of the area was of the organosol or alluvial type. The area had a wet climate with a distinct difference between the rainy and dry seasons. The rainy season is from November until March, and dry season is from April until October.

The forest type of this area is a tropical lowland forest, which is dominated by the family species of Dipterocarpaceae. According to a forestry district report, this forest area had about 105 tree species, including Shorea spp., Dipterocarpus spp., and Dryobalanops spp. The average standing stock of the forest was about $200 \mathrm{~m}^{3}$ per ha for all tree species with a diameter over $20 \mathrm{~cm}$.

\section{Method}

Field plot data were measured in June 1998. The layout for field measurements was based on a strip-sampling scheme with a width of $20 \mathrm{~m}$. For each strip sample, the starting point of the strip was located near a clearly identifiable logging road, so that the point would be easy to detect both in the field and on the image. The direction of the strip was determined by using a compass.

The condition of the trees after the fire as found in the field varied, ranging from undamaged trees, partially live trees, marketable dead trees, and totally dead trees. Undamaged trees are those not burnt by fire. The other tree categories are indicated by trunk or canopy which has been dried and burned and there is no sign of growth after fire; these are grouped as damaged trees. All of the trees (damaged and undamaged) with a diameter above $20 \mathrm{~cm}$ were measured, for diameter at breast height (dbh) by using diameter tape, blumeleise for clear bole height, and the local tree species name was noted, and recorded for every $100 \mathrm{~m}$ long strip.

From the field measurements, we calculated the number of trees per ha $(N)$, stand basal area per ha $(B A)$ and stand volume per ha $(V)$ for damaged and undamaged trees with a diameter above $20 \mathrm{~cm}$. Stand volume is determined by summing the volume of all trees in the plot, and the individual tree volume is calculated by formula:

Tree volume $=0.0000785 D^{2} H F$.

Where : $D$ is diameter at breast height $(\mathrm{cm}), H$ is tree height $(\mathrm{m})$, and $F$ is form quotient (0.7).

For this study we used SPOT XS (K302/J352) level 1B optical satellite data taken on June 5th 1998, nearly two months after the fire. The satellite data of SPOT XS, geometrically corrected by using GCP taken from a topographic map, gave results with a 0.5 pixel accuracy. Because of cloud cover, which was distributed over the image, we performed haze correction by reducing the minimum digital number of each band.

For this study we selected a training area which corresponded with the field plot. The field plot size was 20 by $100 \mathrm{~m}$, and only 1 by 5 pixels on the image. The size of the field plot was too small to locate on the image accurately, so we used a plot size on the image larger than the field plot, such as 4 by 5 pixels. We took the average value of the pixels as a representative digital number for the plot.

We used the digital numbers of XS1, XS2, and XS3 bands. For each sample plots, we calculated the NDVI and the ratio of $\mathrm{XS} 2$ to XS3. NDVI is the ratio between the difference and the sum of red and near infra-red bands, with the sum as the denominator:

$\mathrm{NDVI}=(\mathrm{XS} 3-\mathrm{XS} 2) /(\mathrm{XS} 3+\mathrm{XS} 2)$

The ratio of XS2 to XS3, which will be referred to as Inverse Vegetation Index (IVI), is the ratio between the red band and near infra-red band with NIR band as the denominator:

$\mathrm{IVI}=\mathrm{XS} 2 / \mathrm{XS} 3$

The paired data, from the field and satellite imagery, were analyzed using multiple and/or simple regression techniques. The regression model can be formulated in a matrix form:

$$
Y=X \beta+\varepsilon
$$

Where $Y$ is a vector of the variables of interest (forest stand density, forest stand volume) for $n$ vegetation sample measurements, $X$ is the matrix of the spectral values of bands, $\beta$ is vector of coefficients, and $\varepsilon$ is vector of errors. The forest stand variables used for this regression analysis related only to undamaged trees in the plot.

The regression formulation is solved by the least squares method that will minimize the sum of squared $\varepsilon$ values for the samples. The correlation coefficient and analysis of variance were also calculated, then used for analyzing the regression model.

\section{RESULTS AND DISCUSSION}

The Changes in Forest Stand Variables after the Fire

The tropical lowland forest in the study area was a mixed heterogeneous stand where many tree species with many dimensions were growing together. A field inventory measured all tree species with a diameter above $20 \mathrm{~cm}$, including the dead trees that were killed by the fire. We assumed that the total number of damaged and undamaged trees equalled the plot's stocking before the fire. By comparing stand variables for damaged and undamaged trees and for undamaged trees only, we thus obtained the change in stand conditions due to the fire. In the 49 plots that we selected, the decrease in the number of trees per ha ranged 


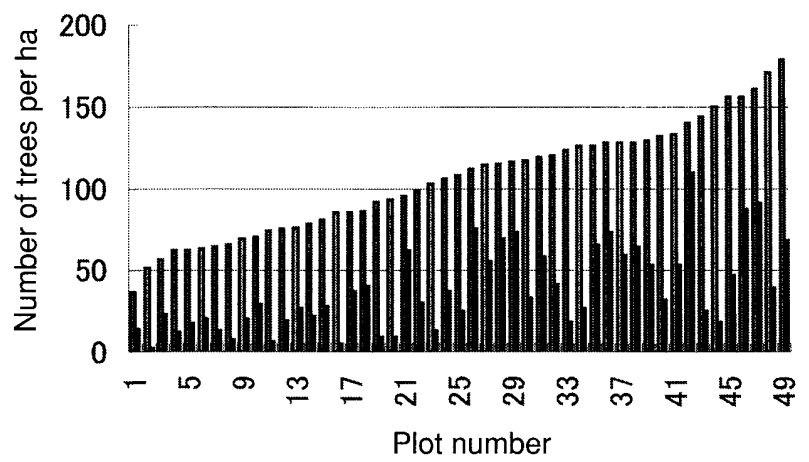

Fig. 1 Forest stand conditions after fire

Damage and Healthy Trees

HealthyTrees

from $6 \%$ to $78 \%$ with an average of about $35 \%$. The details of these changes are shown in Fig. 1.

The ground fire did not burn all the trees in the landscape completely. This is because flammability differs with the species and size of the tree. Ground vegetation such as shrubs, seedlings, saplings and poles on the plot were burnt by the fire. The undamaged trees remaining varied greatly within each plot.

The Relationship between Spectral Value and Forest Stand Variables

For further analysis we used only the undamaged trees in the plot. The plot conditions concerning the undamaged tree variables are shown in Table 1 . The spectral values for 49 selected samples plots and their corresponding forest stand variables were drawn as shown in Fig. 2.

Linear relationships between the forest stand variables $(N, B A, V)$ and spectral values (XS1, XS2, XS3, NDVI, and IVI) were found, and the coefficients of correlation are shown in Table 2.

The SPOT XS bands consisted of two visible spectral (XS1 $=0.5-0.59 \mu \mathrm{m}, \mathrm{XS} 2=0.61-0.68 \mu \mathrm{m})$ and one near infra-red spectral $(\mathrm{XS} 3=0.7-0.89 \mu \mathrm{m})$ band. Stand volume had the largest coefficient of correlation, followed by stand basal area, and the number of trees per ha.

The coefficients of correlation were lower with the XS1 band than with the XS2 band. With the XS1 band, all forest landscape components tended to increase; this band is sensitive to the undamaged vegetation condition. With the XS2 band, the vegetation component became lower, while soil and water components increased; this band is sensitive to chlorophyll content. The training sample condition varied in undamaged trees. The reflectance of the training sample condition with the XS2 band also originated from the soil background and from other non-vegetation or undamaged trees. For the above reason, the training sample condition will show a closer relation with the XS2 band than with the XS1 band.
In the near infrared (NIR) region, the components other than vegetation account for a large portion of the reflectance of the training samples. The vegetation component showed a peak value in this XS3 band, and also the soil component, but water had a lower value in the XS3 band. This is why the forest stand variables of the training sample gave a higher coefficient of correlation with the XS3 than the XS1 band. Using SPOT XS data, the primary forest, secondary forest and deforested area were classified with accuracy of $95 \%$, and XS3 (NIR) was the most useful for separating secondary from primary forest in a tropical forest (KImes et al., 1999). Further, a study relating the age of coniferous forest to Landsat TM data revealed that TM4 (NIR) was also the most sensitive to variation in age (JENSEN $e t$ al., 1999).

The coefficient of correlation showed a highly positive linear relation between NDVI and forest stand variables (Table 2). Green vegetation has strong reflectance contrast between the visible and the near infra red, and this contrast is formulated by several type of vegetation indexes. NDVI, as one type of vegetation index, is highly sensitive to the amount of vegetation. In a burnt forest landscape that has various densities of undamaged trees, the value of NDVI will be higher in areas with higher density of undamaged trees. The red edge measures such as NDVI, were sensitive to chlorophyll concentration, but they also were sensitive to changes in cell structures and drive the changes in infra red reflectance (ADAM et al., 1999).

The forest stand variables showed a highly negative linear correlation with IVI (Table 2). As one kind of vegetation index formula, usually the simple ratio XS3/XS2 is used and tends to be consistent with the NDVI pattern. IVI (XS2/XS3) values were inversely related to the NDVI values, but had a higher coefficient of correlation. The plot after fire has undamaged and damaged trees, and by using an opposite ratio such as IVI, the proportion of damaged trees might be easier to identify. This might be because the reflectance change in XS3 is greater than XS2 due to the change in forest stand variables in training samples. IVI might be more sensitive to undamaged trees or non-vegetation such as the canopy's shadow, soil background, and burned trunks or canopy. PuREvion et al. (1998) found a second order polynomial model to relate the vegetation index to the percent vegetation cover in a grassland area; in their model, the soil background and senescent grass were significantly related to low vegetation cover.

The number of trees showed a negative linear correlation with the XS1 or XS2 or IVI spectral values; that is, fewer trees were associated with a larger value of XS1 or XS2 or IVI. This relation could be explained by the sensitivity of spectral bands in XS1 and XS2 that are more sensitive to soil rather than vegetation, so reducing the number of trees will raise the chance for soil to give higher reflectance, as will the opposite.

The number of trees showed a positive linear correlation with XS3 or NDVI. This is possible because vegetation is always higher in XS3 or NDVI. The coefficients of correlation 


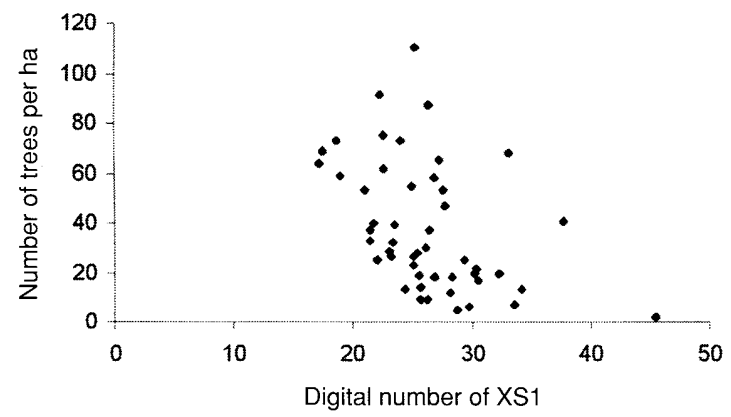

Scatter diagram between $\mathrm{N} / \mathrm{ha}$ and $\mathrm{XS} 1$ values

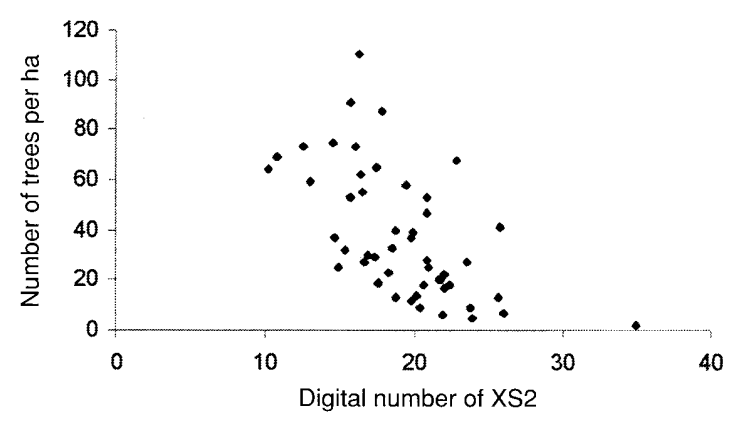

Scatter diagram between $\mathrm{N} / \mathrm{ha}$ and $\mathrm{XS} 2$ values

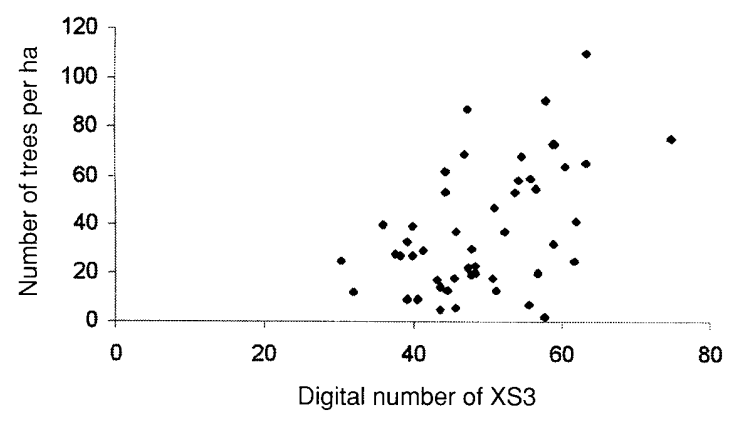

Scatter diagram between $\mathrm{N} / \mathrm{ha}$ and $\mathrm{XS} 3$ values

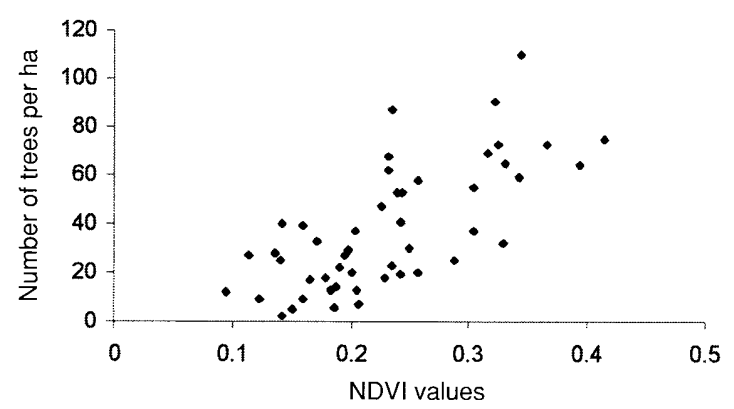

Scatter diagram between N/ha and NDVI values

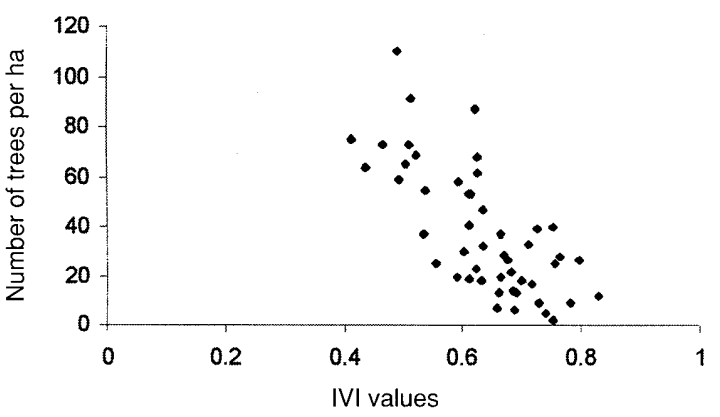

Scatter diagram between N/ha and IVI values

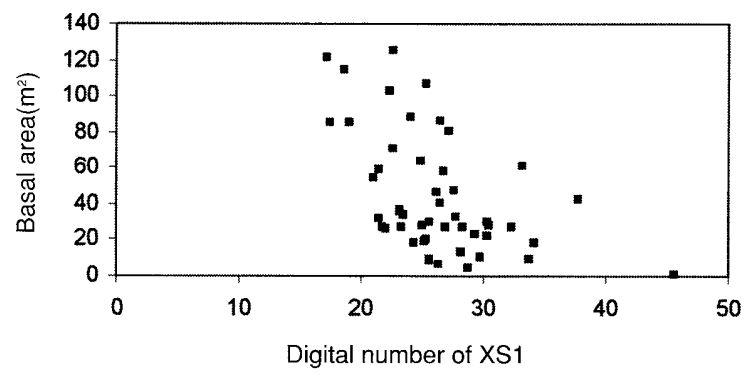

Scatter diagram between basal area and XS1 values

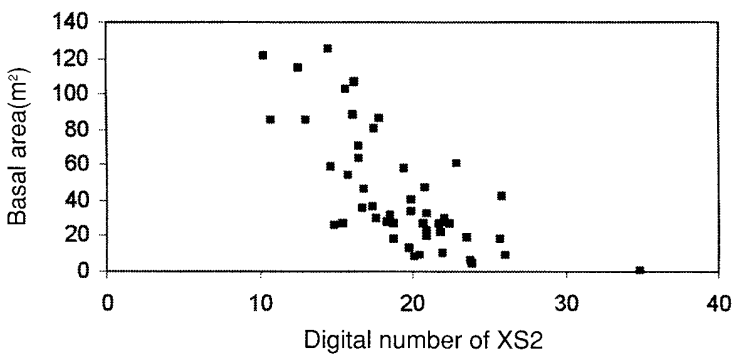

Scatter diagram between basal area and XS2 values

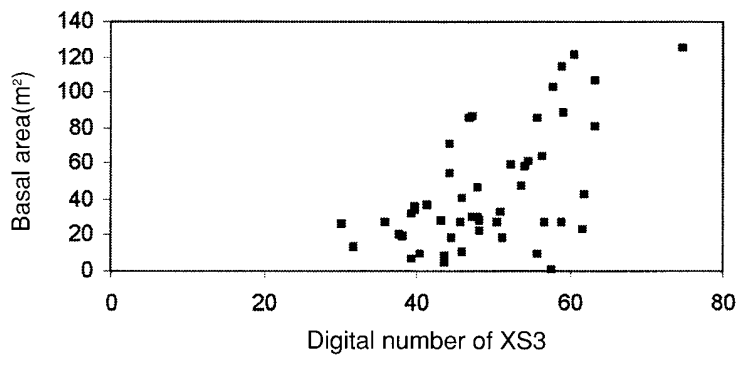

Scatter diagram between basal area and XS3 values

Fig. 2 Relation between forest stand variables and spectral value 


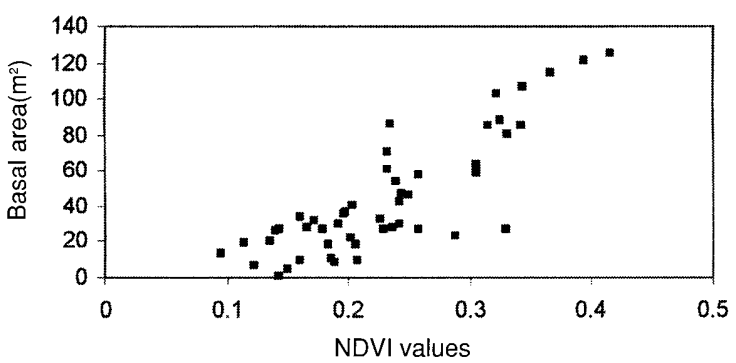

Scatter diagram between basal area and NDVI values.

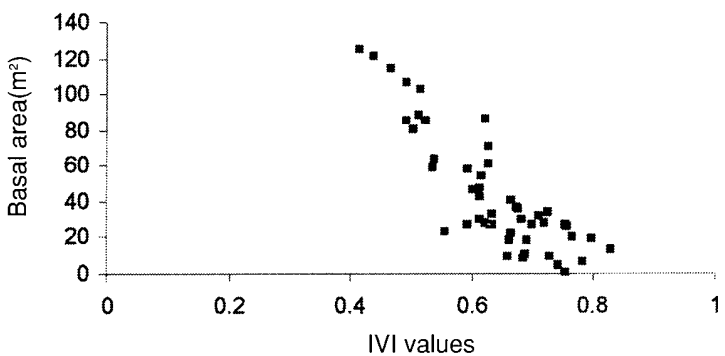

Scatter diagram between basal area and IVI values.

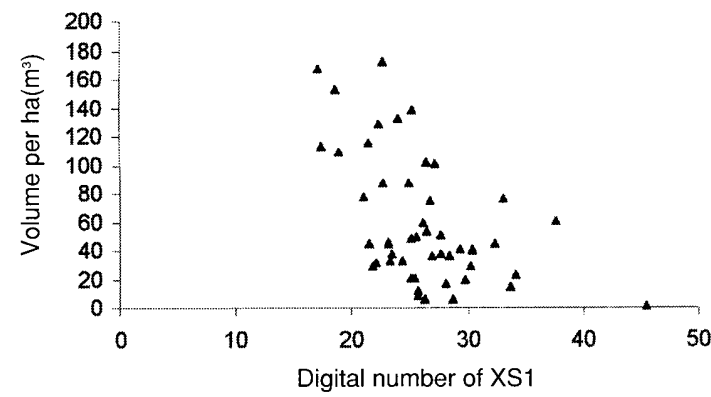

Scatter diagram between vol/ha and XS1 values.

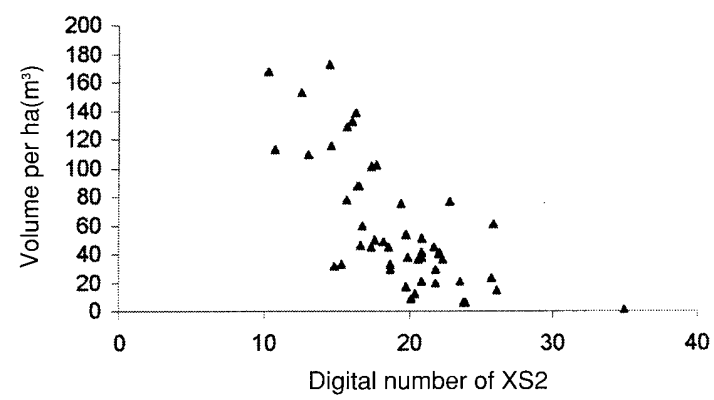

Scatter diagram between vol/ha and XS2 values.

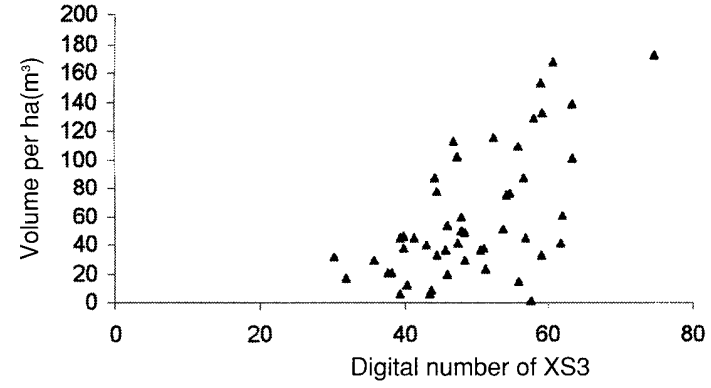

Scatter diagram between vol/ha and XS3 values.

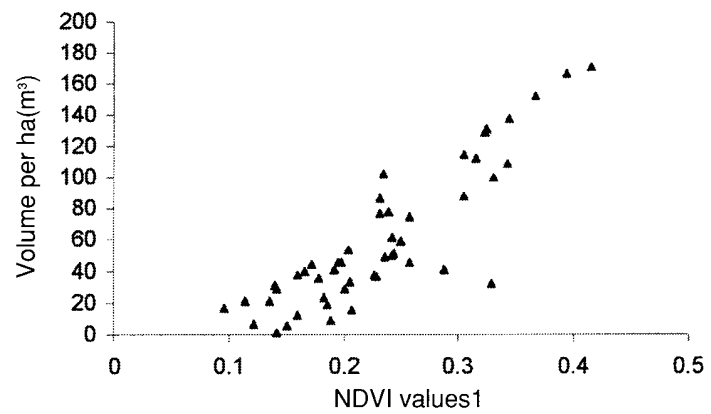

Scatter diagram between vol/ha and NDVI values.

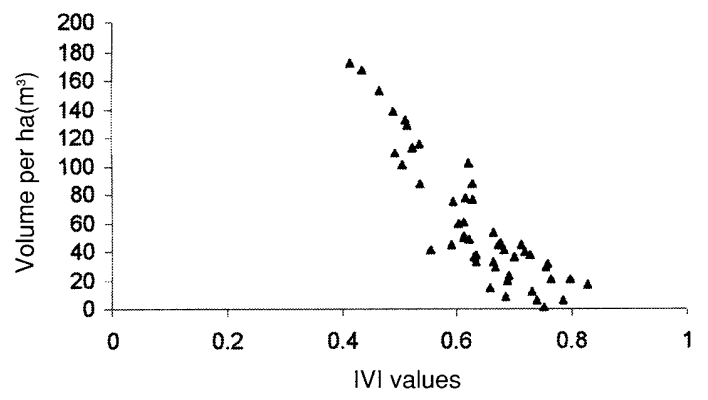

Scatter diagram between vol/ha and IVI values.

Fig. 2 (continued) 
Table 1. Description of undamaged trees in sample plots after fire.

\begin{tabular}{|c|c|c|c|c|c|}
\hline Plot & $\begin{array}{l}\text { Number of } \\
\text { trees(N/ha) }\end{array}$ & $\begin{array}{c}\text { Stand volume } \\
\left(\mathrm{m}^{3} / \mathrm{ha}\right)\end{array}$ & $\begin{array}{c}\text { Basal area } \\
\left(\mathrm{m}^{2} / \mathrm{ha}\right)\end{array}$ & $\begin{array}{l}\text { Mean diameter } \\
\text { at b.h. }(\mathrm{cm})\end{array}$ & $\begin{array}{l}\text { Mean tree } \\
\text { height }(\mathrm{m})\end{array}$ \\
\hline 1 & 14 & 9.09 & 0.87 & 28.1 & 15.0 \\
\hline 2 & 40 & 29.03 & 2.73 & 29.5 & 15.2 \\
\hline 3 & 27 & 21.18 & 1.96 & 30.4 & 15.4 \\
\hline 4 & 39 & 37.44 & 3.43 & 33.5 & 15.6 \\
\hline 5 & 33 & 44.78 & 3.26 & 35.4 & 19.7 \\
\hline 6 & 28 & 21.15 & 2.01 & 30.2 & 15.1 \\
\hline 7 & 9 & 6.3 & 0.64 & 30.1 & 14.1 \\
\hline 8 & 68 & 76.46 & 6.09 & 33.8 & 17.9 \\
\hline 9 & 87 & 101.81 & 8.70 & 35.7 & 16.7 \\
\hline 10 & 53 & 51.27 & 4.75 & 33.8 & 15.4 \\
\hline 11 & 23 & 48.94 & 2.80 & 39.4 & 24.9 \\
\hline 12 & 22 & 40.75 & 2.97 & 41.4 & 19.6 \\
\hline 13 & 17 & 39.75 & 2.80 & 45.8 & 20.3 \\
\hline 14 & 6 & 18.88 & 1.09 & 48.0 & 24.8 \\
\hline 15 & 20 & 29.27 & 2.22 & 37.6 & 18.9 \\
\hline 16 & 5 & 5.8 & 0.47 & 34.5 & 17.7 \\
\hline 17 & 13 & 23.26 & 1.89 & 43.1 & 17.5 \\
\hline 18 & 7 & 15.02 & 0.96 & 41.8 & 22.4 \\
\hline 19 & 12 & 16.47 & 1.35 & 37.9 & 17.4 \\
\hline 20 & 2 & 0.72 & 0.09 & 24.5 & 10.9 \\
\hline 21 & 41 & 61.13 & 4.23 & 36.3 & 20.6 \\
\hline 22 & 25 & 41.36 & 2.29 & 34.2 & 25.8 \\
\hline 23 & 58 & 74.74 & 5.88 & 35.9 & 18.2 \\
\hline 24 & 55 & 87.28 & 6.43 & 38.6 & 19.4 \\
\hline 25 & 110 & 137.67 & 10.69 & 35.2 & 18.4 \\
\hline 26 & 73 & 131.57 & 8.88 & 39.3 & 21.2 \\
\hline 27 & 91 & 128.55 & 10.29 & 38.0 & 17.8 \\
\hline 28 & 62 & 86.86 & 7.07 & 38.1 & 17.6 \\
\hline 29 & 47 & 37.92 & 3.28 & 29.8 & 16.5 \\
\hline 30 & 32 & 32.59 & 2.73 & 33.0 & 17.1 \\
\hline 31 & 53 & 77.35 & 5.47 & 36.2 & 20.2 \\
\hline 32 & 75 & 171.64 & 12.53 & 46.1 & 19.6 \\
\hline 33 & 64 & 166.91 & 12.19 & 49.2 & 19.6 \\
\hline 34 & 59 & 109.22 & 8.53 & 42.9 & 18.3 \\
\hline 35 & 73 & 152.69 & 11.43 & 44.7 & 19.1 \\
\hline 36 & 69 & 112.52 & 8.59 & 39.8 & 18.7 \\
\hline 37 & 37 & 114.72 & 5.92 & 45.1 & 27.7 \\
\hline 38 & 37 & 53.68 & 4.04 & 37.3 & 19.0 \\
\hline 39 & 27 & 45.72 & 3.60 & 41.2 & 18.1 \\
\hline 40 & 29 & 45.17 & 3.66 & 40.1 & 17.6 \\
\hline 41 & 19 & 50.3 & 3.04 & 45.1 & 23.6 \\
\hline 42 & 9 & 11.93 & 1.02 & 37.9 & 16.7 \\
\hline 43 & 13 & 32.95 & 1.89 & 43.0 & 24.9 \\
\hline 44 & 18 & 35.76 & 2.68 & 43.5 & 19.1 \\
\hline 45 & 18 & 36.35 & 2.68 & 43.5 & 19.4 \\
\hline 46 & 25 & 30.97 & 2.62 & 36.6 & 16.9 \\
\hline 47 & 65 & 100.49 & 8.10 & 39.8 & 17.7 \\
\hline 48 & 30 & 58.91 & 4.70 & 44.7 & 17.9 \\
\hline 49 & 20 & 45.16 & 2.72 & 41.6 & 23.7 \\
\hline
\end{tabular}


Table 2. Coefficients of correlation between forest stand variables and spectral value according to SPOT XS band.

\begin{tabular}{|l|c|c|c|}
\hline Bands & $\begin{array}{c}\text { Number of } \\
\text { healthy tree }\end{array}$ & $\begin{array}{c}\text { Stand basal area of } \\
\text { healthy tree }\end{array}$ & $\begin{array}{c}\text { Stand volume of } \\
\text { healthy tree }\end{array}$ \\
\hline XS1 & -0.4379 & -0.5131 & -0.5098 \\
\hline XS2 & -0.5950 & -0.7008 & -0.7094 \\
\hline XS3 & +0.4970 & +0.5883 & +0.6201 \\
\hline NDVI & +0.7084 & +0.8409 & +0.8723 \\
\hline IVI & -0.7213 & -0.8540 & -0.8893 \\
\hline
\end{tabular}

between the number of trees and spectral values were not large.

The relation between basal area and volume per ha with the spectral value showed trends similar to those reported previously; that is negative linear correlation for XS1 or XS2 or IVI, and positive linear correlation for XS3 or NDVI, although all correlation coefficient values were higher compared with $N$. $B A$ and $V$ have higher correlation coefficients because these measurement units take into account the number of trees and also the other forest stand dimensions (diameter and height), so these measurement units represent more fully the stand characteristics.

The condition of samples from the forest after a fire will increase the non-vegetative components such as canopy shadow, burned trunk or canopy to its reflectance values. The decrease in conifer foliage reflectance coupled with an increase in the contribution of the bark and understory to the spectral signal accounts for the spectral pattern observed in Norway spruce stands using TM data (LAMBERT and ARDo, 1995). Also LYMBURNER et al. (2000) who studied the canopy-average surface of several vegetation types and the TM reflectance data found that soil condition, water availability and the interrelationship between canopy properties were related to visible, near infrared and middle infrared regions.

\section{Estimation Model for Forest Stand Variables}

From the previous section, we concluded that XS1, XS2, and XS3 can not be used as independent variables in regression models of forest stand variables. Also NDVI and IVI are highly correlated with each other. Thus, we developed simple linear estimation models for forest stand variables with NDVI or IVI as independent variables. The results of regression analysis for each forest stand variable are shown in Table 3 .

All regression models have a significant result using the $\mathrm{F}$ criterion and also each regression coefficient is significant at either the $99 \%$ or $95 \%$ level. The multiple coefficient of determination is used for selecting the regression model.

In estimating $N$, the model with IVI gave a higher $\mathrm{R}^{2}$ value than that with NDVI. However, both $\mathrm{R}^{2}$ values are low, and there is no suitable regression model that can be used for $N$.

Both models for $B A$ gave a higher value of $\mathrm{R}^{2}$. The model that included IVI as an independent variable gave the higher
Table 3. Regression models for forest stand variables in burnt forest landscape.

\begin{tabular}{|l|c|}
\hline \multicolumn{1}{|c|}{ Regression model } & $\mathrm{R}^{2}$ \\
\hline $1 . \mathrm{N}=-17.192^{*}+238.68^{* *} \mathrm{NDVI}$ & 0.502 \\
\hline $2 . \mathrm{N}=158.85^{* *}-190.61^{* *} \mathrm{IVI}$ & 0.520 \\
\hline $1 . \mathrm{BA}=-3.95^{* *}+36.385^{* *} \mathrm{NDVI}$ & 0.707 \\
\hline $2 . \mathrm{BA}=22.838^{* *}-28.982^{* *} \mathrm{IVI}$ & 0.729 \\
\hline $1 . \mathrm{V}=-57.814^{* *}+507.364^{* *} \mathrm{NDVI}$ & 0.761 \\
\hline $2 . \mathrm{V}=316.707^{* *}-405.661^{* *} \mathrm{IVI}$ & 0.791 \\
\hline
\end{tabular}

* : significant at $95 \%$ level

$* *$ : significant at $99 \%$ level

value of $\mathrm{R}^{2}$ at 0.729 . Thus, for estimating $B A$, we prefer the model with IVI as an independent variable.

For stand volume estimation, all models give a higher accuracy than the previous models. We selected the models based upon the significance of regression coefficients, such as we found for $B A$. On the basis of the $\mathrm{R}^{2}$ value, the model with IVI as an independent variable is the best model for stand volume estimation.

The regression models for each forest stand variable differ in their accuracy of fit. The regression model for $V$ gives the best fit, the second best is for $B A$, and the worst is for $N$. Thus the regression model for $V$ is preferred for implementation.

Dungan (1998) who studied different techniques of image prediction found that regression gave a higher accuracy than kriging, cokriging and probability field simulation when the coefficient of correlation between dependent and independent variable is greater than 0.6 .

The significant relation between forest stand variables after the fire and spectral values of SPOT XS, especially NDVI and IVI, is attributed to the sample representatives. The stand structure of burnt forest in the study area had many different conditions after the fire, so there was a wide range of both forest stand variables and spectral values.

Stand volume provides important information on a forest area because it expresses the forest stand structure while providing other information. The use of regression models based on satellite data can reduce the number of factors that have to be considered in evaluating the forest stand. First, it 


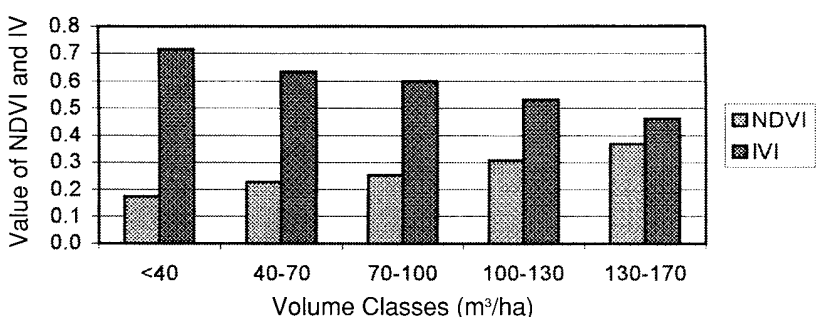

Fig. 3. Relationship between stand volume classes with NDVI and IVI

saves on fieldwork, which is usually expensive. Second, we can take into consideration the spatial distribution of the forest condition, so that the evaluation results might be more accurate. Third, we can use this model incorporated with a double (multiphase) sampling scheme that will probably give a higher accuracy.

The Importance of NDVI and IVI in Classification of Tropical Forest

In the previous section, we found that NDVI and IVI are strongly related to the stand structure of a tropical forest after a fire, as expressed in $B A$ and $V$ for example. However, these indices have a different pattern, and show opposite relations with forest stand variables. The training samples from the forest after a fire have several factors that influence the reflectance value of objects such as soil/water dryness, the trunk and branches of damaged trees, the appearance of senescent canopy of damaged trees, and the ground cover vegetation. Thus, in our training samples there was a distinct but gradual change in forest stand variables between the undamaged trees and other components.

To expand our understanding of the phenomena, we classified the volume of the forest stand into the following classes : $<40 \mathrm{~m}^{3} / \mathrm{ha}, 40-60 \mathrm{~m}^{3} / \mathrm{ha}, 60-100 \mathrm{~m}^{3} / \mathrm{ha}, 100-130$ $\mathrm{m}^{3} / \mathrm{ha}$, and $130-170 \mathrm{~m}^{3} / \mathrm{ha}$. The stand volume refers to undamaged trees with diameter at breast height $>20 \mathrm{~cm}$. The spectral patterns of these objects are shown in Fig. 3.

From Fig. 3, it is clear that the separation among the stand volume classes is more distinct in the NIR region and indices such as NDVI and IVI than in the visible region. A tropical forest has a higher humidity throughout the year. Removal of trees and other disturbances, especially forest fires, could decrease the humidity. On the spectral curve of general land cover that is, vegetation, soil and water, the soil will have a higher value with a red band than with near infra red band. Concerning the vegetation condition, the ratio between the red and infra-red bands of SPOT might reflect the wetness and dryness of forest vegetation. In the burnt forest, vegetation humidity will become lower due to dead trees.

The use of NDVI and IVI may be enabling a more detailed classification of the tropical forests. Because the reflectance of tropical forest not only comes from the leaves, due to the heterogeneous canopy, but also from other components such as shadow among canopy, lower vegetation cover, and soil/water dryness.

These ratios are derived from visible and near infrared bands, some research also showed a better discrimination for tropical forest condition with the use of middle infrared (MIR) such as TM5 and TM7 for Landsat TM, for SPOT XS not yet available. MIR reflectance may be more sensitive to changes in forest properties than the reflectance in visible and NIR wavelengths (Boyd et al., 1999). Even for tropical forest regeneration stages, MIR gave a stronger relationship than did those from visible or NIR bands (BoYD et al., 1996).

\section{CONCLUSIONS AND RECOMMENDATIONS}

Our analysis of tropical forest stand variables after a fire by using SPOT XS data and regression analysis can be summarized as follows :

1. SPOT XS bands gave a close relationship between NDVI or IVI and stand variables after a fire i.e. $N, B A, V$ per ha for the undamaged trees. There was a negative linear correlation between stand variables and XS1, XS2 or IVI and a positive linear correlation between XS3 or NDVI and stand variables.

2. Regression analysis is a useful tool to estimate forest stand variables in tropical lowland forest after a fire using the SPOT XS satellite data directly with limited field measurement.

3. The best estimation of forest stand variables from the SPOT XS spectral values was made for stand volume followed by stand basal area, and stand number of trees.

4. There was no regression model that gave a good fit with the $\mathrm{N}$ variable.

5. Almost all the regression models fitted satisfactorily for stand basal area and stand volume. The best regression models for forest stand basal area and volume were:

$$
\text { a. } B A=22.838-28.982 \mathrm{IVI} ; \mathrm{R}^{2}=0.729
$$$$
\text { b. } V=316.707-405.661 \text { IVI } ; \mathrm{R}^{2}=0.791
$$

6 . The IVI value is the best independent variable for estimating the forest stand variables, followed by NDVI, and can be used in a simple regression model.

\section{LITERATURE CITED}

Adam, M. L., Philpot, W. D. and Norveld, W. A., (1999): Yellowness index: an application of spectral second derivatives to estimate chlorosis of leaves in stressed vegetation. International Journal of Remote Sensing 18: 3663-3675

Boyd, D. S., Foody, G. M and Curran, P. J., (1999): The relationship between the biomass of Cameroonian tropical forest and radiation reflected in middle infrared wavelengths $(3-5 \mu \mathrm{m})$. International Journal of Remote Sensing 20: 1017-1023

Boyd, D. S., Foody, G. M., Curran, P. J., Lucas, R. M. and HonzaKs, 
M., (1996): An assessment of radiance in Landsat TM middle and thermal infrared wavebands for the detection of tropical forest regeneration. International Journal of Remote Sensing 17: 249-261

DunGAN, J., (1998): Spatial prediction of vegetation quantities using ground and image data. International Journal of Remote Sensing 19: $267-285$

Draper, N. and Smith, H., (1981): Applied Regression Analysis. 2ed. John Wiley \& Son, New York, 709 pp

Friedl, M., Michaelson, J., Davis, F. W., Walker, H. and Schimel, D. S., (1994): Estimating grassland biomass and leaf area index using ground and satellite data. International Journal of Remote Sensing 15: $1401-1420$

JAYA, I. N. S. and HuSAENI, E. A., (1999): Evaluation of forest damage due to 1998 fire in East Kalimantan using SPOT imagery: case study in ITC Ltd. concession area. Paper presented in The Third Inter-national Symposium on Asian Tropical Forest managementimpact of fire and human activities on forest ecosystem in the tropics. Samarinda, Indonesia, $16 \mathrm{pp}$

Jensen, J. R., FAng Q. and Minhe, J., (1999): Predictive modeling of coniferous forest age using statistical and artificial neural network approaches applied to remote sensor data. International Journal of Remote Sensing 20: 2805-2822

Kimes, D. S., Nelson, R. F., Salas, W. A. and Skole, D. L., (1999): Mapping secondary forest and forest age from SPOT HRV data.
Inter-national Journal of Remote Sensing 20: $3625-3640$

LAMBeRT, N. J. and ARdo, J., (1995): Spectral characterization and regression-based classification of forest damage in Norway spruce stands in the Czech Republic using Landsat Thematic Mapper data. International Journal of Remote Sensing 16: 1261-1287

LARSSON, H., (1993): Linear regression for canopy cover estimation in acacia woodland using Landsat TM, Landsat MSS and SPOT HRV XS data. International Journal of Remote Sensing 14: 2129-2136

Lymburner, L., Paul, J. B. and Carol, R. J., (2000): Estimation of canopy-average surface-specific leaf area using Landsat TM data. Photo-grammetric Engineering and Remote Sensing 66: 183-191

Nemani, R., Pierce, L., Running, S. W. and Band, L. E., (1993): Forest ecosystem processes at watershed scale - sensitivity to remotely sensed leaf area index estimates. International Journal of Remote Sensing 14: 2519-2534

Purevdorj, T., Tateishi R., Ishiyama, T. and Honda, Y., (1998): Relationships between percent vegetation cover and vegetation indices. Inter-national Journal of Remote Sensing 19: 3519-3535

Sakamoto, Y., Ishiguro, M. and Kitagawa, G., (1986): Akaike information criterion statistics. KTK Scientific Publishers, Tokyo, $290 \mathrm{pp}$

(Received 8 May 2000)

(Accepted 25 January 2001) 